\title{
Hacia una democratización de la sociedad. Un enfoque estructurall
}

\author{
No se puede hablar de una democracia \\ profundamente real cuando las necesidades \\ básicas de la mayor parte de los \\ ciudadanos están insatisfechas, \\ cuando hay una permanente y sistemática \\ violación de los derechos humanos.
}

Ignacio Ellacuría

El término "democracia" se ha convertido en estos últimas décadas en una expresión de moda que denota gran ambigüedad en su significación. Al escuchar los discursos de las diversas insliluciones sociales, públicas y privadas, empresariales y laborales, etc. nos encontramos con la presencia del concepto "democracia". Por ejemplo, el presidente y otros funcionarios de gobiemo constantemente afirman que El Salvador es un país democrálico. Los partidos políticos se autodenominan democráticos y dicen trabajar para consolidar la democracia. Así podríamos aumentar la lista de ejemplos que corroborarían la forma en que el lérmino democracia es empleado por los diversos sectores e instituciones sociales salvadoreñas. El problema es que no se sabe a ciencia cierta el sentido concreto que dichas entidades le asignan al concepto de democracia. Esto nos conduce a preguntamos por el significado de dicho término y precisar su sentido para evitar las ambigüedades inherentes a tal concepto.

La tesis que sostendremos en esta ponencia puede formularse de la manera siguiente: para que una sociedad o un país sea auténtica y estructuralmente democrático, es necesario que sus instituciones sean democráticas. Las reflexiones sobre esta tesis las presentaremos en un apartado y tres subapartados. El apartado lo hemos tituladado "Hacia una concepción estructural de democracia". Como introdución general analizaremos el significado etimológico del término 
"democracia", es decir, el sentido de pueblo y de poder. En los subapartados, esbozaremos algunas reflexiones sobre la democracia en las instituciones políticas; en segundo lugar, la democracia en las instituciones económicas y, finalmente, la democracia en las instituciones socioculturales. En este último subapartado centraremos la reflexión en las instiluciones educativas.

\section{Hacia una concepción estructural de democracia}

En su sentido elimológico, el término "democracia" se deriva del Griego demos, pueblo, y cratos, poder. Lileralmente significa el poder ejercido por el pueblo $^{2}$. Analicemos brevemente la definición. Comenzaremos precisando algunos sentidos que se le dan al concepto de "pueblo" y luego haremos unas breves reflexiones en tomo al poder.

Pueblo, en su sentido literal, significa "todo el mundo". Pero el pueblo que constituye la democracia en la realidad siempre ha sido excluyente, desde la democracia griega hasta la moderna y contemporánea. Por ejemplo, en Atenas, el "pueblo" o demos lo constituían los atenienses reunidos en asambleas populares. Esta concepción excluía a las mujeres y los esclavos. Un segundo significado de pueblo es el de "clase baja" y especialmente los "pobres". Según Aristóteles, la democracia era el poder ejercido por "los que no poseen gran cantidad de bienes, sino por los pobres"'. La democracia, en esle sentido, excluye a otros sectores de la sociedad y, por ende, no responde a los intereses de la comunidad sino a intereses particulares. En la actualidad, cuando se utiliza el término pueblo a veces se está haciendo referencia también a los pobres. Para otros el "verdadero pueblo" lo constituyen los sectores pudientes o ciudadanos adinerados que contribuyen más al crecimiento de la economía de un país, y otras veces está referido a los integrantes del órgano legislativo elegidos electoralmente.

Desde esta perspectiva, afirmar que la democracia es el "gobierno del pueblo, por el pueblo y para el pueblo"', según lo planleado anleriomente, nos deja con muy poca precisión. De ahí que la apelación al concepto de "pueblo" constantemente ha sido un recurso retórico de los políticos, para legitimar su dominio e ideologizar a los grandes sectores de la sociedad en función de sus intereses clasislas.

El otro témino que encontramos en la definición etimológica es el de poder. De forma tradicional, cuando hablamos de poder normalmente pensamos que nos estamos refiriendo al ámbito de lo político o a una forma de gobierno determinado. De hecho, la definición etimológica posee dicho sentido. Desde este punto de vista, la referencia al poder nos traslada al ámbito del Estado, que a partir de la modernidad será la entidad en donde se concentrará el poder. En sus orígenes, el poder que caracterizará al Estado será "un poder absoluto —absolutus - que quiere decir disuelto, desatado, desprendido. Desprendido, por un lado, de la sociedad (...) cuando se le ha arrebatado cualquier forma de domina- 
ción y de señorío; y por otro lado, desprendido de cualquier otro poder temporal o espiritual"s. El carácter de poder absoluto que en la Edad Media era atribuido sólo a Dios, ahora es trasladado al Estado.

El Estado ejercerá su poder mediante dos horizontes fundamentales. Por un lado, "bajo las formas institucionales del Derecho, y por otro lado, bajo las formas de la coacción y la violencia"n. Se trata del poder coercítico. Según el planteamiento marxista, estos dos aspectos no son más que instrumentos mediante los cuales la clase dominante logra su hegemonía. El poder del Estado es una forma de dominación de una clase sobre olra. Por otra parte, Max Weber, según Sergio Pérez Cortez, trata de justificar racionalmente el poder político. Al definir al Estado como "monopolio de la coacción legítima", añade a la idea de coerción la necesidad de una legitimación de dicha exclusividad. Es decir, el Estado es la única entidad que puede hacer uso legítimo de la fuerza física e incluso de la violencia. Toda institución, distinta del Estado, queda deslegitimada para hacer uso de mecanismos violentos. Pero para que el accionar del Estado sea considerado válido, es necesario que el poder que detenta sea legítimo. La justificación política del poder normalmente se realiza mediante la ley. Esto hace del "poder de mandar un derecho y de la obediencia un deber"7.

Dichos planteamientos nos conducen a hacemos la pregunta siguiente: ¿cuáles son las razones por las cuales las personas obedecen? Ignacio Sotelo, en su ensayo sobre "El Estado Moderno", plantea que se puede obedecer por mera habituación. Es decir, nos dejamos llevar por la inercia de la rutina diaria. Por otra parte, se puede obedecer por egoísmo, en tanto que obedeciendo podemos conseguir o conservar nuestros intereses. Otros motivos de obediencia podrían ser el miedo a las represalias y sanciones que conllevaría la desobediencia, pero se puede obedecer, también, por simpatía, respeto, admiración a la persona que está autorizada para mandar.

En definitiva, "la legitimidad es la creencia firme de los sometidos en que el poder está justificado, al dar por supuesto que sirve a los intereses de la mayoría, aunque en realidad sólo convenga a los que detentan el poder"y .

De todo lo afirmado anteriormente podemos aproximamos a una primera definición del poder. Desde esta perspectiva, el poder es definido como la "utilización de la amenaza de una fuerza superior para conseguir que otros hagan lo que deseamos cuando no quieren hacerlo" ${ }^{\prime 9}$. En esta misma línea, para Max Weber [citado por Martín Baró] "el poder consiste en la probabilidad de imponer la propia voluntad, dentro de una relación social, aun contra toda resistencia y cualquiera que sea el fundamento de esa posibilidad" ". Se emplea incluso la violencia física o psicológica para que los súbditos cumplan con sus obligaciones aunque no sea de su agrado hacerlo. La coacción es uno de los medios empleados por el Estado en el ejercicio del poder. 
El análisis del poder no puede referirse sólo a las instituciones de índole política, si no que es necesario extenderlo a las otras instituciones de la sociedad, es decir, a las instituciones económicas y socioculturales. El poder también está presente en este tipo de instituciones. Por ello le llamaremos el poder social. Desde esta perspectiva, el poder puede definirse como la capacidad que tiene un ser humano para determinar la conducta de otro ser humano. En otras palabras, el poder social puede definirse como la "capacidad de hacer que otras personas hagan aquello que quieren que hagan"". Algunos ejemplos pueden ilustrar esta concepción: se puede hablar del poder del padre sobre el hijo, del médico sobre el enfermo, del maestro sobre el alumno, del empresario sobre el obrero, etc. Esta forma de concebir el poder parece que no trae mayores conflictos si está basado en argumentos razonables que pueden ser aceplados por los involucrados de acuerdo con sus intereses y conveniencias. Pero también puede ser ejercido de manera coercitiva y conducir a inconformismos o a rechazar directa $o$ indirectamente dicho poder, mediante la rebeldía o el incumplimiento de algunas normas.

En esta misma línea se enmarcan algunos planteamientos cartacterísticos del poder según Martín Baróín . En primer lugar, el carạ́cter relacional del poder: Esto implica que el poder se hace presente en cualquier lugar donde se den relaciones sociales, ya sea entre individuos o grupos sociales. En segundo lugar, el poder basado en la posesión de recursos: en la relación uno posee algo que otro posee en menor cantidad o no lo tiene. Se trata de una relación asimétrica. Por ejemplo, en la relación propierlario-empresario, administrador, lécnico y obrero, en este caso el que posee los recursos económicos tiene más poder sobre los otros, porque "... frente al poder de la razón está la razón del poder"13. Esto implica que por más argumentos razonables que un obrero presente para que le mejoren sus condiciones laborales, por ejemplo, se hará lo que el dueño o propietario dictamine. Finalmente, el poder produce un efecto en las relaciones sociales: es decir, el poder es capaz de deteminar el comportamiento de las personas. Unos se comportarán de manera obediente y sumisa, mientras que otros ejercerán el dominio o la autoridad sobre otros. De ahí que las personas se definan a sí mismos y a los demás de acuerdo con el poder que posean.

En definitiva, el poder es un elemento que está presente en todas las esferas de la sociedad. El ejercicio del poder no genera mayores conflictos cuando se emplean argumentos razonables y se permite la participación de las partes involucradas en el poder, y puede conducir a conflictos cuando es ejercido despóticamente, cuando una de las partes impone autoritariamente lo que los demás tienen que hacer.

Finalmente, el momento más radical de la configuración del poder se encuentra en las acciones humanas de los individuos. Ellacuría, siguiendo la filosolía Zubiriana, plantea que toda acción humana tiene un momento de poder. El 
poder, desde el punto de vista del individuo, es definido como la capacidad o posibilidad de obrar. En otros términos, el poder es entendido como la capacidad de optar entre las diversas formas de estar en la realidad que se presentan como posibilidades. En el momento en que yo me apropio de una posibilidad que me proporciona la historia, es porque poseo un poder para ello. Un poder trasmitido genéticamente, expresado como un poder para optar, y un poder transmitido históricamente, expresado como el poder optar por una o varias posibilidades e incluso puedo crear nuevas posibilidades si las existentes no son convincentes.

Según Ellacuría, "las posibilidades no dan el poder para oplar, pero sí dan el poder optar, el poder para optar es algo que el individuo humano trae consigo, pero para poder optar con ese poder de opción se requieren estrictas posibilidades posibilitantes"'4. Veamos un ejemplo ilustrativo del poder como opción de posibilidades: deseo fundar una institución educativa. Es una posibilidad que me da la sociedad. Como ser humano tengo el poder para oplar y puedo oplar por esa posibilidad porque tengo los recursos materiales necesarios para realizar dicha fundación. El momento de fundar dicha institución implica un poder de apropiación de una posibilidad real y en la acción realizada se da un momento de poder. Este momento de poder presente en la acción humana fundamenta la existencia del poder social y del poder político. Es decir, el poder político y el poder social tienen su génesis en ese momento de poder presente en la acción humana.

Si el poder está presente en todas los ámbitos de la actividad social (político, económico y sociocultural) y en la acción humana misma (individuo), y la democracia es concebida como una forma de ejercer el poder, entonces es necesaria la democratización de la sociedad... Esta afirmación significa que las estructuras de la actividad social tienen que posibilitar mayores niveles de participación, de los sectores involucrados, en la toma de decisiones relevantes de interés particular y nacional: particular, en cuanto a decisiones que tengan que ver con la organización interna de la institución; nacional, en cuanto a que para aquellas decisiones de trascendencia para el país es necesaria la participación de las diversas instituciones económicas, políticas, educativas, religiosas, etc. Esto nos lleva a precisar en forma breve la democracia en las instituciones políticas, económicas y socioculturales.

\subsection{La democracia en las instituciones políticas}

Cuando hablamos de democracia nommalmente entendemos que se refiere a una forma de gobierno, es decir, a una democracia política. En este sentido se enmarca la concepción de Norberto Bobbio: al definir la democracia como "aquel régimen que permile tomar decisiones con el máximo consenso de los ciudada-

nos, fundados sobre los principios de libertad... y de Estado de derecho"'s. Por otra parte, Adela Cortina, en su libro Etica sin moral, presenta dos conceptos de 
democracia que se enfrentan: la democracia como mecanismo (Teoría elitista) y la democracia como forma de vida (Teoría participativa).

Según la primera concepción, la democracia es solamente un método cuya finalidad es el logro del equilibrio social. Se trata de "aquel sistema constitucional para llegar a las decisiones políticas, en el que los individuos adquieren el poder de decidir por medio de una lucha de competencia por el voto del pueblo"'t". Desde esta perspectiva, en la vida política se reproduce lo que sucede en el ámbito económico. Los individuos consumen aquellos productos que mediante la publicidad son presentados como los mejores. De manera similar sucede en la política: "Los ciudadanos se comportan como consumidores que optan ante unos productos (ideologías), ante unas ofertas (promesas electorales) de los empresarios (políticos)"'17. Esto significa que la visión del hombre poseedor o económico explica la organización de la vida política. Los candidatos de los partidos políticos se venden por la propaganda, como se venden los electrodomésticos. Se trata, en síntesis, de una concepción de democracia en donde una minoría de representantes de los partidos políticos buscan, mediante el voto de los ciudadanos, acceder al poder. El problema estriba en que una vez que han conquistado el poder, el eleclor carece de mecanismos efectivos para poder controlar la gestión política y no les queda más que aceptar las medidas que "democráticamente" implementan los elegidos ${ }^{18}$.

Este tipo de democracia muestra una aparente participación con igualdad de derechos en la vida política, pero esconden las profundas desigualdades reales existentes en la sociedad. Es decir, los grupos o partidos políticos contendientes en la política consideran que tienen las mismas oportunidades, pero en la realidad tienen más posibilidades de triunfar los que poseen más capital para ideologizar al pueblo por medio de la propaganda.

La otra teoría de la democracia, concebida como forma de vida, implica que el ser humano puede realizar su capacidad aulolegisladora mediante "la participación en la organización de la vida social... se considera que el hombre es capaz de darse a sí mismo sus propias leyes y que, por consiguiente, someterse a leyes ajenas es inhumano"' ". Según Adela Cortina, el que los individuos se den sus propias leyes significa que éstos tienen que participar en su elaboración, de tal manera que expresen los intereses individuales y generales. Las decisiones que afectan a la comunidad no pueden ser tomadas sólo por unos individuos, sino que mediante el diálogo deben buscar la mejor salida en beneficio de todos. En otras palabras, la participación en las decisiones hace posible que el ser humano se sienta parte de la comunidad, y las leyes resultantes de esa participación son queridas y acepladas por él. Esto conlleva a que los ciudadanos se vean impelidos a que no busquen sus propios intereses, sino que busquen también el interés general. 
Según esto, la participación no puede reducirse al voto. Pueden existir decisiones que se tomen mayoritariamente y que respondan a intereses particulares. Una decisión para que sea legítima debe cumplir con los siguientes aspectos ${ }^{21}$ : En primer lugar, todos los afectados deben participar en el diálogo o debe haber participación directa de auténticos representantes de intereses. En segundo lugar, los afectados deben poseer conocimientos suficientes del problema en cuestión. En tercer lugar, los participantes en el diálogo deben estar dispuestos a tornar las decisiones que defiendan intereses generalizables. Finalmente, lo racional de las decisiones sería la unanimidad, pero esto rara vez es posible; por ello es necesario buscar los medios para que en la resolución final se tomen en cuenta los intereses de todos los afectados. Esta concepción da por supuesto que todos los individuos tienen acceso al diálogo. En nuestros pueblos hay una gran mayoría que está excluida de la participación en el diálogo y, a la vez, está excluida de la participación equitativa de la riqueza producida socialmente.

La democracia, pues, entendida como una forma de vida individual y comunitaria, tiene que respetar y fomentar "el carácter autolegislador de los individuos, educarlos en la responsabilidad y en el sentido de la justicia" "'.

La forma en que se ha implementado, en nuestros pueblos, la democracia política ha sido insufienciente. Según Norberto Bobbio, la democracia política o liberal no ha cumplido muchas de las promesas que teóricamente ofrecía ${ }^{22}$. En primer lugar, uno de los objetivos de la democracia política era buscar los intereses generales de la nación (ideal), pero se buscan los intereses particulares de los representados (real). En segundo lugar, el poder del Estado no se ha manejado transparentemente, sino que ha caído en la corrupción. En tercer lugar, los primeros teóricos atribuían un gran valor educativo a la participación electoral, en la actualidad existe una gran indiferencia reflejada en los altos índices de ausentismo en los diversos países. En cuarto lugar, la empresa y los aparatos administrativos no han sido democratizados.

Por otra parte, el significado del concepto de democracia, que se emplea cotidianamente en nuestros pueblos, está enmarcado dentro de la teoría elitista de la democracia. En última instancia, la democracia se ha convertido en un puro "mecanismo para decidir quién debe ejercer el poder político, y concretamente en la aplicación indiscriminada de la regla de las mayorías"23. ¿Será esto verdaderamente democracia? La respuesta es negativa. No basta con gozar de ciertas libertades de expresión, de prensa, voto, etc. Es necesario que nuestros países implementen una democracia política que supere la concepción formalista incipiente que se implementa en algunos ámbilos de la política, y que garantice una participación real y efectiva de los integrantes de una sociedad en los asuntos públicos y privados. El Estado tiene que buscar las formas o mecanismos de participación que vayan haciendo posible la participación acliva en el poder y en 
la toma de decisiones, en beneficio del bien común y más concretamente de los sectores desprotegidos de la sociedad.

Desde esta perspectiva, será moralmente más legítimo aquel Estado que posibilita la participación real de sus miembros y que, a la vez, vaya creando las condiciones para una democratización de las instituciones económicas y socioculturales. No se trata de una participación sin más, si no que la democracia debe ir posibilitando procesualmente la superación de las situaciones de extrema desigualdad y pobreza en las que se encuentran inmersas las grandes mayorías desposeídas de nuestros pueblos. Que la democracia se oriente a tal objetivo nos conduce a plantearnos el problema de la democracia en las instituciones económicas.

\subsection{La democracia en las instituciones económicas}

Hablar de democracia en las instituciones económicas o en las empresas no es usual en nuestros pueblos. Normalmente el discurso queda reducido a la democracia en las instituciones políticas. La existencia de elecciones, libertad de expresión, organización, etc. son necesarias en un país democrático pero no son suficientes. Según Ellacuría, "no se puede hablar de democracia profundamente real cuando laş necesidades básicas de la mayor parte de los ciudadanos están insatisfechas, cuando hay una permanente y sistemática violación de los derechos humanos..."24. Desde esta perspectiva, una teoría democrática, en América Latina, Centroamérica y, más en concreto, en El Salvador, no puede pasar por alto las grandes desigualdades existentes presentes en nuestros países. No puede obviar la situación de miseria que padece una gran mayoría de seres humanos que les impide satisfacer las necesidades mínimas de alimentación, salud, educación y vivienda digna. En una realidad tal, es realmente cínico hacer afirmaciones contundentes de que una sociedad o un país es democrático.

La democracia, para que sea auténtica, tiene que ser estructural y diseminarse en todas las esferas de la sociedad. Es decir, liene que entenderse como una "configuración de la sociedad y del Estado que responda a las necesidades (...) de las mayorías, al derecho de la participación equitativa en la propiedad y en la renta nacional, así como en la determinación de las grandes decisiones sociales y políticas"2s.

Desde este punto de vista, las instituciones económicas tienen que democratizarse. Esto nos plantea los cuestionamientos siguientes: ¿será posible democratizar las instituciones económicas? Más en concreto, ¿será posible lograr realmente una auténtica democratización de la sociedad sin transformar radicalmente las estructuras económicas y la ideología, de acumulación de capital, que orienta la praxis de las empresas destinadas a la producción de bienes y servicios? Las respuestas a estas interrogantes son complejas y desbordan las posibilidades de un tratamiento exhaustivo en este trabajo. Sin embargo, podemos 
afirmar que, en forma general, en unas empresas o instituciones económicas en donde predominan dicha ideología y unas estructuras que la operativizan, resulta difícil, aunque no imposible, visualizar la posibilidad de lograr mayores grados de participación en la riqueza que dichas entidades generan, debido a las implicaciones reales y concretas a las que conduciría la democratización de las instituciones económicas.

La democratización económica, en general, significaría la participación equitativa en la riqueza producida socialmente. Es decir, una democracia económica conduciría a la desconcentración de la riqueza, la preocupación por el bienestar de toda la población, especialmente de los más desprotegidos, una política fiscal de acuerdo con los ingresos económicos, crecimiento y desarrollo económico en armonía con el medio ambiente, derecho al trabajo digno y bien remunerado, etc. ${ }^{2 h}$

Por otra parte, democratizar las instituciones económicas implicaría, según nuestra perspectiva, que los trabajadores participen en la dirección y los beneficios de la empresa. En esta línea, David Schweickert plantea que la participación de los trabajadores en la dirección de la empresa y en el reparto de beneficios incrementa la productividad de las empresas. Es decir, "la participación tiende más a incrementer la productividad cuando viene combinada con (1) la participación en beneficios, (2) el empleo garantizado a largo plazo, (3) unos diferenciales salariales relativamente pequeños y (4) unos derechos laborales garantizados (como el despido sólo por causa justa)"'27.

En una sociedad donde las empresas son democráticas, el trabajador no debe ser considerado como una mercancía o como capital humano, como lo llaman muchos, si no que al entrar en una empresa, el trabajador debe convertirse "en un miembro con volo, y liene derecho a una determinada participación en los beneficios" ${ }^{2 s}$. La forma de esta participación no necesariamente tiene que ser igual; son los integrantes de la empresa los que decidirán democráticamente los porcentajes de los mismos, según sean los casos concretos y tomando en cuenta la dificultad de las tareas, las habilidades y talentos de los trabajadores.

Ahora bien, no nos cabe la menor duda de que si se quieren superar los problemas sociales que padecen grandes sectores de nuestros pueblos, es necesario que se desconcentre el poder económico. En otras palabras, es necesario que se implementen mecanismos, racionales y justos, que posibiliten mayores grados de participación y de redestribución de los recursos económicos. En la búsqueda de tales mecanisnos juegan una función importante las instituciones socioculturales.

\subsection{La democracia en las instituciones socioculturales}

En los apartados anteriores hemos enfatizado la necesidad de democratizar las instituciones políticas y las instituciones económicas. Pero en la sociedad existen otras instituciones que no son ni políticas, ni son económicas en sentido 
estricto. A estas instituciones las llamaremos socioculturales. En esta denominación se encontrarían instituciones como la familia, las escuelas, los colegios, las univesidades, religiosas, organizaciones laborales, feministas, etc. Para que una sociedad sea democrática se necesita que estas instituciones sean democráticas. Se trata de que estas instituciones se democraticen internamente y contribuyan a la democratización de los otros subsistemas de la sociedad desde su propia especificidad.

La realidad nos muestra que en muchas de estas instituciones predomina, a nivel térico, una concepción conservadora y una praxis conservadora ${ }^{29}$ que, según las exigencias de nuestra realidad, es necesario cambiar, además de implementar unas relaciones más equitativas y más libres.

En otras instituciones se sostiene, a nivel teórico, un discurso democrático y en la práctica se siguen reproduciendo unas relaciones autoritarias y verticales. La sumisión y la obediencia ante las autoridades o jefaturas se convierte en una de las cualidades más apreciadas y más valoradas en los súbditos" ${ }^{21}$. No existen mayores posibilidades de que los diversos miembros de las instituciones puedan participar en la dirección de la misma, ni expresar con libertad sus puntos de vista sobre la realidad de la institución en la que laboran. Se expresan sofisticada o directamente las características del poder coactivo, tal como lo hemos expuesto en páginas anteriores.

La fachada democrálica es otra de las características de las instiluciones con esta tendencia; es decir, se permile la participación de algunos de sus miembros, pero sus aportes o sus sugerencias no son tomadas en cuenta; en última instancia se hace lo que las máximas autoridades, en muchos de los casos, ya han decidido previamente.

En la Reforma Educativa se ha introducido la idea de democracia en las instituciones educativas. En el documento presentado por la Comisión Nacional de Educación, "Ciencia y Desarrollo", que sirvió de marco teórico conceptual para dicha Reforma, se afirma que la democracia, como concepto funcional, es un método y la educación es un instrumento". El argumento que presentan en el documento se resume en las líneas siguientes: "Siendo la democracia el método de vida que los salvadoreños hemos escogido para nuestro desartollo, el instrumento básico de formación de los ciudadanos tiene que ser congruente, de manera absoluta, con el esquema de funcionamiento que se está implantando en la realidad total"32. Es importante el reconocimiento que hacen de implementar la democracia en las instituciones educativas, sin embargo, la concepción de democracia como método que sostienen es insuficiente, según lo expresado en apartados anteriores.

Esto nos conduce a hacernos la pregunta siguienle: ¿de qué manera estas instituciones podrían democratizarse intemamente y contribuir a la democratiza- 
ción de la sociedad? Responder a esta interrogante implicaría una investigación que no podemos realizar en todas las instituciones, en estos momentos. Sin embargo, haremos algunas reflexiones en tomo a la democratización de las instituciones educativas.

En primer lugar, democratizar las instituciones educativas implicaría posibilitar un mayor acceso, de los sectores desposeídos, a la educación Básica, Media y Superior. En la actualidad, un gran porcentaje de la población se ve marginada de los servicios educativos. No se puede afirmar que un país es democrálico si posee un gran indice de analfabetismo y de deserción escolar, por falta de recursos económicos que hagan posible dicho acceso. Ello implicaría el establecimiento de políticas estatales y económicas que posibiliten a los sectores marginados, campesinos, obreros, desempleados, etc., medios viables de acceso a la enseñanza en los diversos niveles de enseñanza.

En segundo lugar, es necesario que estas instituciones se democraticen internamente. La democratización interna de dichas instiluciones implicaría la formación de personalidades y profesionales capaces de tomar decisiones en función de los intereses personales y comunitarios. Que sean capaces de buscar el equilibrio o de buscar la armonía entre sus intereses y los de los otros. Las instituciones educativas pueden contribuir al logro de este objetivo teórica y prácticamente, es decir, enseñándole a los jóvenes a participar activamente en la toma de desiciones en las cuales ellos se ven involucrados. La participación no puede reducirse al voto, si no que exige "el diálogo permanente, el debate abierto, el control de las decisiones y la capacidad de crítica efectiva"

No cabe duda de que este planteamiento presupone un cambio del discurso pedagógico conservador, de las actitudes y de la praxis que realizan los maestros y directores $y / o$ rectores de las instituciones educativas. Algunas instituciones educativas salvadoreñas, antes de la reforma, unas, y con la reforma, otras, han adoptado un discurso democrático, pero sus prácticas siguen siendo conservadoras $^{34}$. Se continúa con prácticas autoritarias que impiden el ejercicio de la democracia entre los intregrantes de la comunidad educativa.

Por otra parte, es indispensable cambiar, también, las estructuras institucionales o las formas de organización que se fundamentan en ciertos mecanismos de poder autoritario y, por ello, impiden o imposibilitan la participación real. De ahí la necesidad de la inplementación de instituciones educativas democráticas que fomenten la participación, la justicia, la libertad de expresión, de acción y agrupación.

La democracia en las instituciones educativas no puede entenderse como una anarquía en las que sus integrantes evadan sus responsabilidades. No se pueden emplear las libertades democráticas para exigir, por ejemplo, bajar el nivel académico o repetir evaluaciones que, por irresponsabilidad o falta de organización personal, arrojaron bajos resultados. 
Por otra parte, la democracia no se puede reducir a la formación de consejos escolares. Por ejemplo, con la Reforma educativa salvadoreña, que sigue la idea de democracia como método, se ha implementado en las Escuelas e Institutos nacionales el Consejo Directivo Escolar (CDE), formado por el director( $a$ ), alumnos y padres de familia. Este es un paso importante que se ha dado a nivel público que hay que aprovechar para democratizar las escuelas y los institulos nacionales, aunque no se puede decir lo mismo de las instituciones educativas privadas. Sin embargo, estos mecanismos pueden convertirse en un espejismo democrático si los alumnos y padres de familia que integran el CDE no participan efectivamente en la toma de decisiones. Es decir, a pesar de que existe dicho consejo, el direclor $\longrightarrow$ la directora - es quien decide autoritariamente lo que se tiene que hacer.

Otro aspecto esencial de la democratización intema es la distribución justa de los ingresos que perciben las instituciones educativas. Los bajos salarios redundan en detrimento de la calidad académica, tanto a nivel básico y medio como superior. En nuestro país, la mayoría de profesores de educación básica y media tienen que laborar dos o tres turnos para poder obtener un salario que apenas puede cubrir las necesidades básicas. Un profesor que trabaje de esta forma no dispone de suficiente tiempo para preparar y actualizar sus conocimientos. A nivel superior, algunos profesores que son contratados a tiempo completo en una universidad imparten clases en otras universidades para oblener otros ingresos que le posibiliten su sobrevivencia. No se diga los profesores que son contratados por horas-clases que tienen que impartir entre cuatro, cinco y seis signaturas por semestre, a veces en distintas universidades, para obtener un salario más o menos digno.

Por otra parte, la falta de transparencia en los ingresos financieros y la distribución de los mismos genera, muchas veces, malestar en los estudiantes y docentes. A simple vista se ve que los ingresos de las instituciones son significativos, pero no se ven reflejados en mejoras en las condiciones laborales, salariales y estudiantiles. Muchas veces se argumenta que no existen fondos para mejorar dichas condiciones, pero no se presentan cifras concretas que demuestren la imposilidad real para llevarlas a cabo. La transparencia en el ámbito financiero es fundamental para evitar la cultura del rumor y los malestares en los miembros de las instituciones educativas.

En definitiva, pues, la participación equitativa de los ingresos y su manejo transparente es un factor importante en la democratización interna de las inslituciones educativas. Esto sería posible si las inslituciones asumieran su misión educaliva y cumplieran efectivamente la definición de ser "instituciones sin fines de lucro".

La insistencia de que las instituciones se democraticen internamente obedece a que, de esa manera, contribuirían a democratizar la sociedad. Para que una 
sociedad sea democrática no es suficiente la existencia de cierto pluralismo político, sino que es necesario que se posibilite la participación real en los otros subsistemas de la sociedad. Por el hecho de que la sociedad es una realidad estructural, la democracia tiene que ser también estructural, es decir, que lo político, lo económico y lo sociocultural se codeterminan mutuamente. Por lo tanto, la democracia, para que sea auténtica, creíble y eficaz, tiene que darse a nivel de las instituciones políticas, económicas y socioculturales.

\section{Btbliografía}

Aristóteles, La política, San Salvador: UCA Editores, El Salvador, 1988.

Ayala Perdomo, E. O., "La función política de la Universidad en la sociedad actual", Mundialización y liberación, Ensayos filosbficos, II Encuentro Mesoamericano de filosofia, Colección pensamiento, Managua, 1996.

Ayala Perdomo, E. O., "Teoría y praxis en las inslituciones educativas", Realidad, 61, San Salvador: UCA, enero-febrero, 1998.

Carr, W., Una teoría para la educación. Hacia una educación educativa crítica, Ediciones Morata, España, 1996.

Colom, A.J. y Mélich, J.C., Después de la Modernidad. Nuevas filosoflas de la Educación, España: Ediciones Paidós, 1994.

Cortina, A., Etica sin moral, España: Editorial Tecnos, Tercera Edición, 1995.

Ellacuría, I., Filosofía de la realidad hisıórica, San Salvador: UCA Edilores, El Salvador, 1990.

Ellacuría, I., Escritos pollticos, Veinse años de historia en El Salvador (1969-1989), San Salvador: UCA Edilores, 1993.

Enciclopedia lberoamericana de Filosofia, Filosofia politica I. Ideas políticas y movimientos sociales, Madrid: Editorial Tratta, 1997.

Enciclopedia lberoamericana de Filosofía, Filosofía poltica II. Teoría del Estado, Madrid: Editorial Tratla, 1996.

Gonzálcz, A., Introducción a la próctica de la filosofia, San Salvador: UCA Editores, 1989.

González García, J.M., Teorías de la democracia, Barcelona: Editorial Antropos, 1992.

Martín Baró, I., Sistema, Grupo y poder, San Salvador: UCA Edilores, Tercera Edición, 1996.

Martínez Peñate, O., El Salvador. Democracia y autoritarismo, San salvador: Editorial Nuevo Enfoque, 1996.

Raphael, D., Problemes de filosofia politica, Madrid: Alianza cditorial, 1989.

Rodrígucz Adrados, F., Historia de la democracia. De Solón a nuestros díos, Colccción: Ensayo, España, 1997.

Sartori, G., Teoria de la democracia, Tomo I, Madrid: Alianza Editorial, 1988.

Schweickart, D., "Democracia Económica. Propuesta para un socialismo eficaz", Realidad, 55, San Salvador: UCA, enero-febrero, 1997.

"Volver a pensar la educación. Política, educación y Sociedad", Vol. 1, Congreso internacional de didáctica, Madrid: Ediciones Morata, 1995. 


\section{Notas}

1. Este artículo es el texto, corregido y aumentado, de la ponencia pronunciada -el 28 de julio- en el So. Congreso Nacional e Internacional de Filosofia, realizado en la Universidad del Valle de Atemajac (UNIVA), Guadalajara, Jalisco, México, del 27 al 31 de julio de 1998. El tema central del Congreso se tituló: "Tendencias Filosóficas Contemporáneas hacia una Educación y una Democracia Integrales".

2. Cfr. Sartori, G., Teoría de la democracia, Tomo I, Madrid: Alianza Editorial, 1988, pp. 41-47.

3. Aristóteles, Política, San Salvador: UCA Editores, El Salvador, 1988, p. 160.

4. Cortina, A., Etica sin moral, Madrid: Edilorial Tecnos, Tercera Edición, 1995, p. 255.

5. Solelo, I., "Estado Moderno", en Enciclopedia Iberoamericana de filosofia. Filosofía politica II, Teoría del Estado, Madrid: Editorial Trota, 1996, p. 30.

6. Pércz Cortez, S., "El poder, del poder político al análisis sociológico", en Enciclopedia Iberoamericana de filosofia, Filosofia politica I, Ideas politicas y movimienros sociales, Madrid: Editorial Trola, 1997, p. 99. Las cursivas son nuesiras.

7. Ibid., p. 102.

8. Sotelo, I., op. cit., p. 39.

9. Ibid., p. 79.

10. Martín Baro, I., Sistema, grupo y poder, San Salvador: UCA Editores, Tercera Edición, El Salvador, 1996, pp. 100-101.

11. Raphacl, D., Problemas de Filosofía política, Madrid: Alianza Editorial, 1989, p. 78.

12. Cfr. Ibid., pp. 97-100.

13. Ibid., p. 98.

14. Ellacuría, I., Filosofía de la realidad hisiorica, San Salvador: UCA Editores, El Salvador, 1990 , p. 521.

15. González, García, J.M., "Límites y aporías de la democracia representativa en Norbelto Bobbio", publicado en Teorías de la democracia, Barcelona: Antropos, 1992, p. 43.

16. Corlina, A., op. cit., p. 260.

17. Ibld., p. 261. Las cursivas son nuestras.

18. Cfr. Gónzález, A., Introducción a la práctica de la filosofia, San Salvador: UCA Editores, El Salvador, 1994, pp. 322-323.

19. Cortina, A., op. cit., p. 262.

20. Cfr. Ibíd., p. 271.

21. Ibid., p. 264. Las cursivas son nuestras.

22. Cfr. Norberto Bobbio cilado por González García, J.M., op. cil., pp. 48-49.

23. Cortina, A., op. cir., p. 257.

24. Ellacuria, I., "El desmoronamiento de la fachada demócratica", en Veinte años de hisioria en El Salvador (1969-1989). Escritos políticos, San Salvador: UCA Editores, El Salvador, 1993, p. 271.

25. Ibid., p. 280.

26. Cfr. Martínez Peñate, O., El Salvador. Democracia y autorilarismo, Editorial Nucvo Enfoque, El Salvador, 1996, p. 65.

27. Cfr. Schweickart, D., "Democracia económica", Realidad, 55, San Salvador: UCA, El Salvador, 1997, pp. 59. 
28. Ibid., p. 50.

29. Por conservador entendemos aquella teoría que justifica el ejercicio del poder verticalmente y aquella praxis que exige de los súbditos sumisión y obediencia sin cuestionamientos.

30. Estas cualidades no se exigen exclusivamente en las instituciones socioculturales, sino que también en las instituciones políticas y económicas.

31. Cfr. "Transformar la Educación para la paz y el desarrollo de El Salvador", El Diario de Hoy, 20 de julio de 1995, p. 8.

32. lbid., p. 9.

33. Santos Guerra, M. A., Democracia escolar, Volver a pensar la educación, Madrid: Ediciones Morata, 1995, p. 132.

34. Para profundizar en este punto sc puede consultar mi arlículo "Teoría y praxis en las instituciones educativas", en Realidad, 61, San Salvador: UCA, El Salvador, enero-febrero, 1998, pp. 67-76. 